\title{
Walking and Aerobic Capacity in Old Adults after Concentric and Eccentric Endurance Exercise at Self-Selected Intensities
}

\author{
Mandy L. Gault*, Mark E. T. Willems \\ Department of Sport \& Exercise Sciences, University of Chichester, Chichester, UK \\ Email: ${ }^{*}$ m.gault@chi.ac.uk
}

Received 22 December 2013; revised 27 January 2014; accepted 5 February 2014

Copyright (C) 2014 by authors and Scientific Research Publishing Inc.

This work is licensed under the Creative Commons Attribution International License (CC BY). http://creativecommons.org/licenses/by/4.0/

\section{(c) (i) Open Access}

\section{Abstract}

Self-selected exercise intensity can be a useful exercise prescription tool for older adults; however, it is not known if it can elicit improvements in walking and aerobic capacity. In older adults, effects of concentric or eccentric endurance exercise at self-selected walking speed were examined on 1-mile indoor walk performance, predicted maximum oxygen uptake and physiological parameters. Twenty-four older adults (67 \pm 4 years) completed $3 \times 30$ min treadmill walks per week for 12-weeks on level (LTW, $n=11,0 \%$ ) or downhill (DTW, $n=13,-10 \%$ ) treadmill gradient at a selfselected speed, which progressed every 4 weeks. Maximal oxygen uptake was predicted using a 1-mile walk at 4-week intervals with physiological responses recorded using a portable metabolic system. One-mile walking speed increased from baseline following 8- and 12-weeks (12 weeks: LTW: $13 \% \pm 6 \%$, DTW: $14 \% \pm 9 \%, P<0.01)$. Both groups increased predicted maximal oxygen uptake following 8-weeks of walking (LTW: 15\% $\pm 15 \%$; DTW: $23 \% \pm 30 \%, P<0.01$ ). At 12-weeks, the 1-mile walk was performed with higher heart rates and minute ventilation $(P<0.01)$. It is concluded that an exercise programme of concentric or eccentric endurance exercise, at self-selected exercise intensity, is sufficient to elicit similar improvements in maximum oxygen uptake.

\section{Keywords}

Ageing; Concentric Endurance Exercise; Eccentric Endurance Exercise; Self-Selected Intensity; Aerobic Capacity

\section{Introduction}

Maximal aerobic capacity $\left(\dot{\mathrm{V}} \mathrm{O}_{2} \mathrm{max}\right)$, a measure of cardiovascular fitness, is suggested to decline at a rate of ${ }^{*}$ Corresponding author. 
up to $20 \%$ per decade in older sedentary adults [1]. A decline in aerobic capacity has important implications on the functional mobility and lifetime independence of older adults [1] [2]. Generally, a decline in $\dot{V} \mathrm{O}_{2}$ max has the consequence that older adults work closer to maximum effort when performing a given sub-maximal task, for example, crossing the road [3]. Therefore, prevention and attenuation of the age-related reduction in maximal aerobic capacity, through maintaining or increasing physical activity levels, are imperative to enhance functional mobility. There is evidence to suggest that endurance trained older adults, who continue to exercise, can have a $40 \%$ - 50\% lower reduction in $\dot{V} \mathrm{O}_{2}$ max per decade in comparison to their sedentary counterparts [4] [5].

It was recently reported that 12-weeks of level treadmill walking (LTW) and downhill treadmill walking (DTW), at a self-selected walking speed (SSWS) improved functional mobility [6] and maximal voluntary isometric force of older adults [7]. To elicit aerobic changes, conventional aerobic exercise interventions have their intensity set at a percentage of maximum heart rate $\left(\mathrm{HR}_{\max }\right)$, heart rate reserve $\left(\mathrm{HR}_{\text {reserve }}\right)$ or $\dot{V} \mathrm{O}_{2} \max$ [8] [9]. However, there is an increased interest in the ability of individuals to exercise with a self-selected intensity to enhance exercise adherence [10] [11]. Furthermore, LTW is an activity biased towards muscle-shortening contractions (concentric), whereas DTW, an activity that is biased towards voluntary muscle-lengthening contractions (eccentric), has been shown to place a lower cardiac load on the individual compared to LTW at a similar speed, reducing intensity with a $25 \%$ lower oxygen consumption [12]. Although such an activity is at a lower oxygen demand, it is not known if the load, during DTW at SSWS, or LTW at SSWS is sufficient to improve walking and aerobic capacity of older adults, when used as part of an exercise intervention. Previously, 12-weeks of eccentric exercise with an eccentric stepper improved aerobic capacity by $12 \%$ in older (74 \pm 6 years) cancer care patients [13]. In comparison to a seated eccentric stepper, DTW has the potential to utilize a larger muscle mass. It has also been demonstrated that DTW at SSWS can elicit a mean heart rate of $90 \pm 9$ $\mathrm{b} \cdot \mathrm{min}^{-1}$ in older adults [6]. This equated to $56 \%$ of age-predicted maximum heart rate, an intensity, according to the ACSM guidelines [14], that is sufficient to expect physiological adaptations from an exercise intervention [6].

Therefore, the aim of the current study was to investigate, in older adults, the effects of 12-weeks of LTW (concentric endurance exercise) and DTW (eccentric endurance exercise), at a self-selected walking speed (SSWS) on 1-mile walk performance, aerobic capacity and physiological parameters. It was hypothesized that LTW but not DTW would elicit an improvement in 1-mile walk performance and aerobic capacity due to the lower intensity of DTW at SSWS.

\section{Methods}

\subsection{Participants}

Twenty-four community dwelling older adults volunteered to take part in the study. Before participating, each individual completed a health history questionnaire and provided written informed consent, with ethical approval for all procedures and protocols approved by the University of Chichester Ethics Committee. Following risk stratification [14], it was noted that all participants were in good health with four on medication to lower cholesterol. Participants had not been involved in structured exercise programme for at least 12-months and lived an independent lifestyle.

\subsection{Experimental Design}

Participants were randomly assigned to a downhill (DTW) ( $=13$; men, $n=6$; women, $n=7$ ) or level treadmill walking (LTW) group (control group, $n=11$; men, $n=6$; women, $n=5$ ). They attended the laboratories 1-week before the beginning of the intervention for familiarisation and preliminary measurements. Participants agreed to refrain from consuming alcohol or take part in any vigorous physical activity in the 24-hours prior to all assessments. During the first preliminary session, resting heart rate and blood pressure (BP) (Omron 705 IT, Medisave, UK) were measured after subjects were seated for 20-minutes. This was followed by measurement of height (Holtain Ltd, Crymuch, UK) and body mass in normal clothing without shoes (Seca Model 880, Seca, UK). Body fat analysis was determined using bioelectrical impedance analysis (BIA) and body mass index (BMI) was calculated [BMI = body mass $(\mathrm{kg}) \cdot$ height $\left.^{-2}(\mathrm{~m})\right]$. Participants were familiarised for all testing procedures with the exception of downhill treadmill walking. This included the Rockport Fitness Walking Test (RFWT, see details below) and treadmill walking (Woodway Ergo ELG 70, Cranlea \& Co., Birmingham, UK; HP Cosmos 
Pulsar, Bodycare products, Warwicks, UK). During the second preliminary session, baseline predicted maximum oxygen uptake was determined using the RFWT, wearing a portable metabolic system (Cosmed $\mathrm{K}^{2} \mathrm{~b}^{2}$, Cosmed, Rome, Italy), and baseline self-selected walking speed (SSWS), on a level treadmill gradient, was determined for each individual. SSWS was a speed that the participants perceived to be able to maintain for 30-minutes. Participants were blinded to treadmill speed and duration. The starting speed was $2.5 \mathrm{~km} \cdot \mathrm{hr}^{-1}$ with an increase of $0.3 \mathrm{~km} \cdot \mathrm{hr}^{-1}$ every 30-seconds by the tester until the participant indicated that the next increment in speed would be considered too fast [15]. Participants then maintained their selected speed for 10-minutes to ensure their perception that they had the ability to maintain this for 30-minutes. Participants repeated the RFWT, wearing the portable metabolic system following 4-, 8- and 12-weeks of the walking intervention, and SSWS was re-established after 4- and 8-weeks. Participant characteristics were similar between the LTW and DTW groups $(P>0.05$; Table 1$)$.

\subsection{Aerobic Capacity}

Aerobic capacity was assessed using the RFWT. A practice walk was administered to familiarise participants with the procedures, as walking time in older adults was found to be slower for the first walk compared to consecutive walks [16]. Participants were instructed to walk 1-mile at a fast constant pace, 281/2 times around a wooden floored gymnasium $(19 \times 9 \mathrm{~m})$ wearing a portable metabolic system. They walked alone with verbal encouragement from the investigator to maintain the fast constant pace. Stride frequency was monitored at regular 1-minute intervals (minutes 1 - 2, 5 - 6, 10 - 11, 15 - 16) to ensure pace was maintained throughout the 1-mile walk [17]. The RFWT uses body weight, age, time to complete 1-mile and final heart rate to predict $\dot{\mathrm{V}} \mathrm{O}_{2} \max \quad[16]$ and is a validated sub-maximal test for the prediction of $\dot{\mathrm{V}} \mathrm{O}_{2} \max$ in adults 30 - 79 years (Equation (1); [16]). Heart rate was measured at the end of the RFWT using a Polar Heart Rate monitor (FS1, Polar UK). During completion of the RFWT, older adults wore the portable metabolic system to assess physiological and metabolic adaptations to the 12-week walking programme [minute ventilation $\left(\dot{V}_{\mathrm{E}}\right)$, oxygen consumption $\left(\dot{V} \mathrm{O}_{2}\right)$, respiratory exchange ratio (RER) and heart rate (HR)]. The system was warmed up for 40-minutes prior to calibration as per the manufacturer's guidelines. Calibration involved 10 pumps of a 3L syringe into the Cosmed turbine for volume of expired air during ventilation, a room air calibration $\left(20.93 \% \mathrm{O}_{2}\right.$ and $\left.0.03 \% \mathrm{CO}_{2}\right)$ and a calibration with a standard gas mixture of $\mathrm{O}_{2}(15.6 \%)$ and $\mathrm{CO}_{2}$ (5.66\%) (Linde Gas, UK). Gault et al. [17] demonstrated that wearing a portable metabolic system during the RFWT has no impact on performance of the 1-mile walk.

$$
\dot{\mathrm{V}} \mathrm{O}_{2} \max =6.9652+(0.0091 \times \mathrm{WT})-(0.0257 \times \mathrm{AGE})+(0.5955 \times \mathrm{SEX})-(0.2240 \times \mathrm{T})-(0.115 \times \mathrm{HR})
$$

where: WT, body mass in pounds; AGE, years; $\mathrm{SEX}$, men $=1$, women $=0$; $\mathrm{T}$, time in minutes and hundredths of a minute; HR, heart rate at the end of the 1-mile walk.

\subsection{Exercise Intervention}

All participants visited the laboratories for three 30-minute supervised walking sessions per week, at their

Table 1. Participant characteristics, mean \pm SD.

\begin{tabular}{ccc} 
& \multicolumn{2}{c}{ Group } \\
\cline { 2 - 3 } & LTW & DTW \\
\hline Age (yrs) & $65 \pm 4$ & $69 \pm 4$ \\
Height (m) & $1.71 \pm 0.07$ & $1.69 \pm 0.10$ \\
Body mass (kg) & $80.0 \pm 19.0$ & $75.0 \pm 8.5$ \\
BMI (kg·m ${ }^{-2}$ ) & $27.1 \pm 5.2$ & $26.2 \pm 2.8$ \\
Body fat (\%) & $30.9 \pm 8.8$ & $30.5 \pm 7.7$ \\
BP (mm Hg) & $154 / 89 \pm 27 / 10$ & $137 / 81 \pm 4 / 10$ \\
RHR (b·min & $74 \pm 10$ & $76 \pm 10$ \\
\hline
\end{tabular}

LTW, level treadmill walking; DTW, downhill treadmill walking; BMI, body mass index; BP, blood pressure; RHR, resting heart rate. 
SSWS, for up to 12-consecutive weeks and were requested to maintain their normal diet. The LTW and DTW group had a treadmill gradient of $0 \%$ and $-10 \%$, respectively. A gradient of $-10 \%$ is the point at which minimum total body energy cost occurs for downhill walking [18]. SSWS for level treadmill walking was determined by each individual and re-assessed at 4-week intervals (DTW: weeks $1-4,4.54 \pm 0.59 \mathrm{~km} \cdot \mathrm{hr}^{-1}$; weeks $5-8,5.25 \pm$ $0.64 \mathrm{~km} \cdot \mathrm{hr}^{-1}$; weeks $9-12,5.81 \pm 0.50 \mathrm{~km} \cdot \mathrm{hr}^{-1}$; LTW: weeks $1-4,4.26 \pm 0.41 \mathrm{~km} \cdot \mathrm{hr}^{-1}$; weeks 5 - 8, $5.17 \pm$ $0.44 \mathrm{~km} \cdot \mathrm{hr}^{-1}$; weeks $9-12,5.52 \pm 0.36 \mathrm{~km} \cdot \mathrm{hr}^{-1}$ ).

\subsection{Data and Statistical Analysis}

Data for $\dot{V}_{\mathrm{E}}, \dot{\mathrm{V}} \mathrm{O}_{2}$, RER and HR was recorded on a breath-by-breath basis by the portable metabolic system, exported to Excel and the mean over the last $50 \%$ of the 1-mile walk calculated. Statistical analysis was undertaken using SPSS for Windows V16.0 (SPSS, Chicago, Illinois). Normal distribution of the data was tested using a Kolmogorov-Smirnov test. A two-way repeated measures analysis of variance (ANOVA) was used to examine the change from baseline values across time and between conditions (level walking vs. downhill walking) for all parameters. Due to three participants (one LTW and two DTW) stopping the programme after 4-weeks and further three after 8-weeks (two LTW and one DTW), there was missing data. Therefore, a method described by Little \& Rubin [19] was used to correct for this, by replacing the missing data with the mean of each data set. When the two-way ANOVA showed a significant difference between conditions or over time preplanned t-tests, with Bonferroni corrections, were used to compare the change over time and values at each time point $(P<0.05)$. All data are presented as mean $\pm \mathrm{SD}$, significance was accepted at $P<0.05$ and presented with degrees of freedom (df) and effect size (partial eta squared, $\eta^{2}$ ).

\section{Results}

\subsection{One-Mile Walking Speed and Stride Frequency}

Walking speed during the 1-mile walk showed a statistically significant main effect for time $\left(\mathrm{F}_{(2,39)}=28, P<\right.$ $\left.0.01, \eta^{2}=0.56\right)$ and no difference between walking groups $\left(\mathrm{F}_{(1,22)}=0.12, P=0.72, \eta^{2}=0.01\right)$. Baseline RFWT walking speed (LTW: $1.78 \pm 0.17 \mathrm{~m} \cdot \mathrm{s}^{-1}$; DTW: $1.78 \pm 0.24 \mathrm{~m} \cdot \mathrm{s}^{-1}$ ) was not changed following 4-weeks of treadmill walking (LTW: $1.80 \pm 0.20 \mathrm{~m} \cdot \mathrm{s}^{-1}$; DTW: $1.84 \pm 0.22 \mathrm{~m} \cdot \mathrm{s}^{-1}$ ) at a SSWS $\left(\mathrm{t}_{(23)}=-2, P=0.03\right.$; non-significant due to Bonferroni correction) (Figure 1).

Following 8-weeks of treadmill walking there was an increase from baseline of $8 \pm 5 \%$ for LTW $(1.90 \pm 0.19$ $\left.\mathrm{m} \cdot \mathrm{s}^{-1}\right)$ and $10 \pm 7 \%$ for DTW $\left(1.91 \pm 0.20 \mathrm{~m} \cdot \mathrm{s}^{-1}\left(\mathrm{t}_{(23)}=-4, P<0.01\right)\right.$. Post- tests (12-weeks) showed a further increase of $4 \%$ in RFWT walking speed for both LTW and DTW $\left(\mathrm{t}_{(23)}=-5, P<0.01\right)$, an overall increase of $13 \pm$ $6 \%$ for LTW $\left(1.98 \pm 0.18 \mathrm{~m} \cdot \mathrm{s}^{-1}\right)$ and $14 \% \pm 9 \%$ for DTW $\left(2.03 \pm 0.17 \mathrm{~m} \cdot \mathrm{s}^{-1}\right)$ from baseline to post $\left(\mathrm{t}_{(23)}=-6, P\right.$ $<0.01)$. Stride frequency was similar between groups at all-time points $\left(\mathrm{F}_{(1,22)}=2, P=0.15, \eta^{2}=0.91\right)$, with an increase for both groups during the 1-mile walk over time $\left(\mathrm{F}_{(3,66)}=60, P<0.01, \eta^{2}=0.73\right.$; Figure 2). Baseline

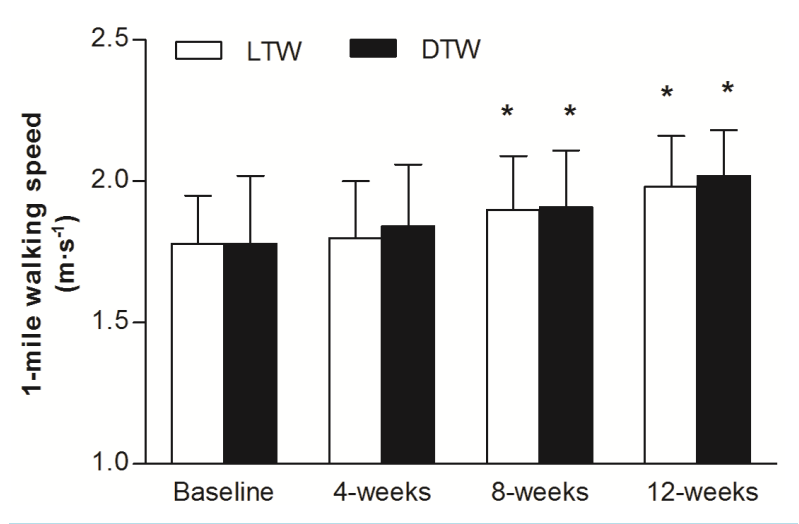

Figure 1. Walking speed $\left(\mathrm{m} \cdot \mathrm{s}^{-1}\right)$ during the Rockport Fitness Walking Test 1-mile walk at baseline and following 4-, 8- and 12-weeks of level $(0 \%)$ and downhill $(-10 \%)$ treadmill walking at a self-selected walking speed. Data are presented as mean \pm SD. ${ }^{*}$, indicates a difference from baseline $(\mathrm{P}<0.01)$. 


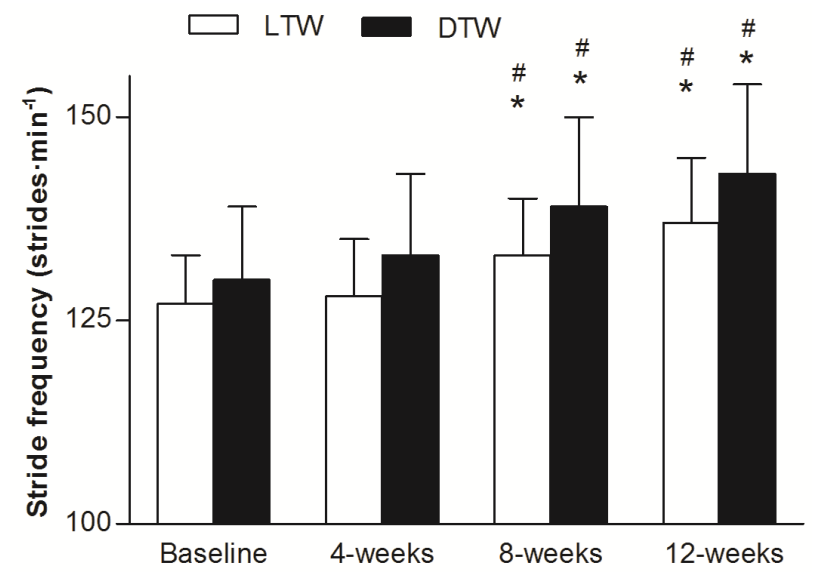

Figure 2. Stride frequency (mean \pm SD) during the Rockport Fitness Walking Test 1-mile walk following 4-, 8-, and 12-wks of level $(0 \%)$ and downhill $(-10 \%)$ treadmill walking at a selfselected walking speed. *, different from baseline $(P<0.01)$; ${ }^{\text {, }}$ different from the preceding weeks test $(P<0.01)$.

stride frequency $\left(129 \pm 8\right.$ strides $\left.\cdot \min ^{-1}\right)$ was not different during the 1-mile walk following 4-weeks of LTW and DTW $\left(130 \pm 9\right.$ strides $\left.\cdot \min ^{-1} ; \mathrm{t}_{(23)}=-1, P=0.97\right)$. There was an increase in 1 -mile walk stride frequency following 8-weeks of LTW and DTW $\left(135 \pm 9\right.$ strides $\left.\cdot \min ^{-1} ; \mathrm{t}_{(23)}=-7, P<0.01\right)$, with a further increase after 12-weeks $\left(140 \pm 9\right.$ strides $\left.\cdot \min ^{-1} ; \mathrm{t}_{(23)}=-10, P<0.01\right)$.

\subsection{One-Mile Walking Time, Heart Rate and Predicted $\dot{V}_{2} \max$}

Time to complete the RFWT at baseline and following

4-, 8- and 12-weeks of LTW and DTW are presented in Figure 3. A significant main effect for time was reported $\left(\mathrm{F}_{(2,38)}=24, P<0.01, \eta^{2}=0.52\right)$, with no differences between walking groups $\left(\mathrm{F}_{(1,22)}=0.05, P=0.83, \eta^{2}\right.$ $=0.002)$. At baseline, LTW participants completed the 1 -mile walk in $15.1 \pm 1.4$ mins and $15.2 \pm 2.2$ mins for DTW participants. Following 4-weeks no change in time to complete the 1-mile walk was reported ( $\mathrm{t}_{(23)}=2, P=$ 0.03; non-significant due to Bonferroni correction). However, there was a decrease of $7 \% \pm 4 \%$ and $9 \% \pm 6 \%$ after 8-weeks of LTW (14.2 \pm 1.4 mins) and DTW (14.1 \pm 1.5 mins), respectively $\left(\mathrm{t}_{(23)}=5, P<0.01\right)$. These times were reduced further following 12-weeks of treadmill walking with a decrease of $11 \% \pm 5 \%$ from baseline for LTW (13.6 $\pm 1.2 \mathrm{mins})$ and $11 \% \pm 7 \%$ for DTW (13.5 $\pm 1.4 \mathrm{mins})$, an additional $4 \% \pm 3 \%$ and $3 \% \pm 3 \%$ reduction in 1-mile walking time from 8-weeks $\left(\mathrm{t}_{(23)}=6, P<0.01\right)$.

Final RFWT heart rate data were similar between groups (LTW: $128 \pm 18 \mathrm{~b} \cdot \mathrm{min}^{-1}$; DTW: $127 \pm 16 \mathrm{~b} \cdot \mathrm{min}^{-1}$ ) with no significant main effect for time $\left(\mathrm{F}_{(2,37)}=1, P<0.29, \eta^{2}=0.06\right)$. Predicted $\dot{V} \mathrm{O}_{2} \max$ from the RFWT at baseline and following 4-, 8-, and 12-weeks of LTW or DTW are presented in Figure 4. At baseline, LTW participants obtained a predicted $\dot{V} \mathrm{O}_{2}$ max of $29.8 \pm 7.0 \mathrm{~mL} \cdot \mathrm{kg}^{-1} \cdot \mathrm{min}^{-1}$, with $27.4 \pm 8.2 \mathrm{~mL} \cdot \mathrm{kg}^{-1} \cdot \mathrm{min}^{-1}$ for DTW. A two-way repeated measure ANOVA showed a significant main effect for time $\left(\mathrm{F}_{(2,39)}=12, P<0.01, \eta^{2}=\right.$ $0.36)$, with no difference between groups $\left(\mathrm{F}_{(1,22)}=0.10, P<0.75, \eta^{2}=0.01\right)$. Further analysis, showed no change in predicted $\dot{V} \mathrm{O}_{2}$ max after 4-weeks of LTW and DTW $\left(\mathrm{t}_{(23)}=-2, P=0.11\right)$, however there was an increase of $15 \% \pm 15 \%$ and $23 \pm 30 \%$ after 8 -weeks for LTW $\left(32.3 \pm 5.9 \mathrm{~mL} \cdot \mathrm{kg}^{-1} \cdot \mathrm{min}^{-1}\right)$ and DTW (33.0 \pm 5.2 $\left.\mathrm{mL} \cdot \mathrm{kg}^{-1} \cdot \mathrm{min}^{-1}\right)$, respectively $\left(\mathrm{t}_{(23)}=-4, P<0.01\right)$. No further increase in predicted $\dot{V} \mathrm{O}_{2}$ max from baseline was shown following 12-weeks of LTW or DTW $\left(\mathrm{t}_{(23)}=-1, P=0.24\right)$.

\subsection{Physiological and Metabolic Measurements}

Physiological and metabolic data from the 1-mile RFWT (Table 2) reflect averages taken over the latter half of the walk. Oxygen uptake $\left(\dot{V}_{2}\right)$ during the 1-mile walk did not differ between treadmill walking groups $\left(\mathrm{F}_{(1,16)}\right.$ $\left.=0.11, P=0.75, \eta^{2}=0.01\right)$ or from baseline to post $\left(\mathrm{F}_{(1,16)}=3, P=0.13, \eta^{2}=0.14\right)$. This was similar for the percentage of $\dot{V} \mathrm{O}_{2}$ max used throughout the 1-mile walk (Time: $\mathrm{F}_{(2,41)}=0.23, P=0.8, \eta^{2}=0.01$; Between groups: $\left.\mathrm{F}_{(1,20)}=0.12, P=0.73, \eta^{2}=0.01\right)$. Minute ventilation $\left(\dot{V}_{\mathrm{E}}\right)$ during the 1-mile walk test, was similar 


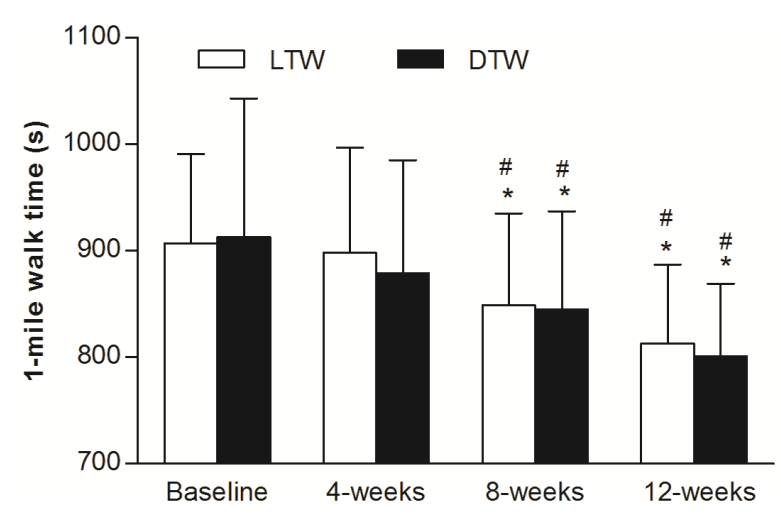

Figure 3. Walking time (mean $\pm \mathrm{SD}$ ) by older adults to complete the Rockport Fitness Walking Test 1-mile walk at baseline and following 4-, 8- and 12-weeks of level (0\%) and downhill $(-10 \%)$ treadmill walking at a self-selected walking speed. ${ }^{*}$, different from baseline $(P<0.01)$; \#, different from the preceding weeks test $(P<0.01)$.

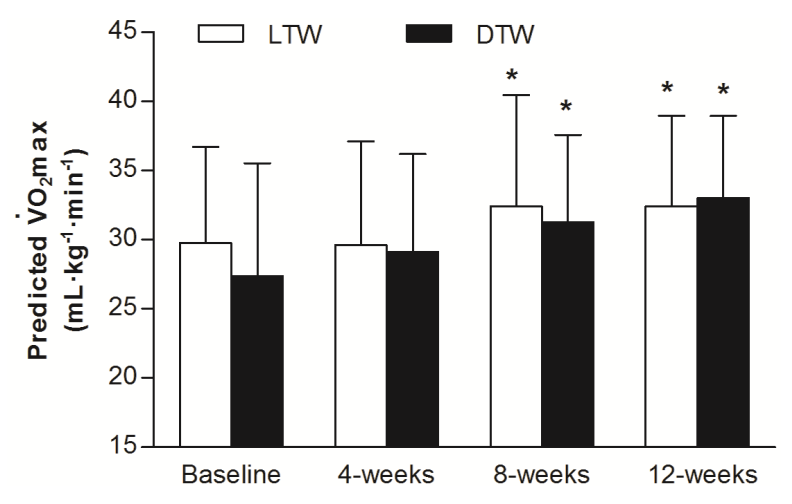

Figure 4. Predicted $\dot{V} \mathrm{O}_{2} \max$ (mean $\pm \mathrm{SD}$ ) of older adults from the Rockport Fitness Walking Test 1-mile walk at baseline and following 4-, 8- and 12-weeks of level $(0 \%)$ and downhill $(-10 \%)$ treadmill walking at a self-selected walking speed. ${ }^{*}$, different from baseline $(P<0.01)$.

Table 2. Cosmed $\mathrm{K} 4 \mathrm{~b}^{2}$ physiological and metabolic data obtained (mean $\pm \mathrm{SD}$ ) during the $2^{\text {nd }}$ half of the 1-mile RFWT at baseline and following 12-weeks of LTW and DTW.

\begin{tabular}{ccccc}
\hline & \multicolumn{2}{c}{ LTW } & \multicolumn{2}{c}{ DTW } \\
\hline & Baseline & $12-\mathrm{wk}$ & Baseline & $12-\mathrm{wk}$ \\
\hline$\dot{V} \dot{\mathrm{E}}_{(}\left(\mathrm{L} \cdot \mathrm{min}^{-1}\right)$ & $40.1 \pm 10.9$ & $56.4 \pm 22.5^{*}$ & $44.1 \pm 14.4$ & $55.5 \pm 11.2^{*}$ \\
$\dot{\mathrm{V}} \mathrm{O}_{2}\left(\mathrm{~mL} \cdot \mathrm{kg}^{-1} \cdot \mathrm{min}^{-1}\right)$ & $14.2 \pm 4.3$ & $16.3 \pm 8.8$ & $13.6 \pm 3.7$ & $15.3 \pm 5.1$ \\
$\dot{\mathrm{VO}}(\%)$ & $64 \pm 15$ & $65 \pm 18$ & $65 \pm 15$ & $64 \pm 12$ \\
$\mathrm{RER}\left(\dot{\mathrm{V}} \mathrm{CO}_{2} / \dot{V O}_{2}\right)$ & $0.87 \pm 0.07$ & $0.87 \pm 0.02$ & $0.85 \pm 0.04$ & $0.87 \pm 0.07$ \\
$\mathrm{HR}\left(\mathrm{b} \cdot \mathrm{min}^{-1}\right)$ & $126 \pm 19$ & $143 \pm 15^{*}$ & $119 \pm 15$ & $135 \pm 21^{*}$ \\
\hline
\end{tabular}

LTW, level treadmill walking; DTW, downhill treadmill walking; $\dot{V}_{\mathrm{E}}$, minute ventilation; $\dot{\mathrm{V}} \mathrm{O}_{2}$, oxygen consumption; $\dot{V} \mathrm{CO}_{2}$, carbon dioxide production; RER, respiratory exchange ratio; HR, heart rate; $\dot{V} \mathrm{O}_{2} \quad$ (\%) $\dot{\mathrm{V}} \mathrm{O}_{2}$ during the RFWT as a percentage of predicted maximal oxygen uptake; " , indicates significant increase from baseline values $P<0.01$. 
between treadmill walking groups $\left(\mathrm{F}_{(1,16)}=0.06, P=0.81, \eta^{2}=0.004\right)$, with a significant increase from baseline to post for LTW and DTW $\left(\mathrm{F}_{(1,16)}=19, P<0.01, \eta^{2}=0.01\right)$. LTW participants reported a $40 \% \pm 34 \%$ increase in $\dot{V}_{\mathrm{E}}$, with a $31 \% \pm 30 \%$ increase for DTW. This was similar for heart rate during the latter half of the walk, a $15 \% \pm 13 \%$ and $14 \pm 16 \%$ increase from baseline to post for LTW and DTW treadmill walking groups, respectively $\left(\mathrm{F}_{(1,16)}=0.16, P<0.01, \eta^{2}=0.50\right)$.

\section{Discussion}

The results of the current study indicate that treadmill walking — on a negative or neutral gradient—at a self-selected walking speed is at an intensity that improves walking and aerobic capacity of older adults. Furthermore, although eccentric endurance exercise, i.e. downhill treadmill walking, occurs with a significantly reduced cardiac load when compared to level treadmill walking [12], they elicit similar improvements in aerobic capacity of older adults.

Performance in the RFWT is often evaluated using walking speed and time to complete the walk [20]. Baseline 1-mile walking speed for men and women within the present study was $1.78 \pm 0.21 \mathrm{~m} \cdot \mathrm{s}^{-1}$ (1-mile in $15.2 \pm$ 1.8 minutes). Achieving a walking speed of $1.44 \mathrm{~m} \cdot \mathrm{s}^{-1}$ to $1.78 \mathrm{~m} \cdot \mathrm{s}^{-1}$ during the 1 -mile walk demonstrates reasonable functional mobility for older adults and an indicator of independent living [20]. A normal walking speed of $>1.2 \mathrm{~m} \cdot \mathrm{s}^{-1}$ is considered to be a sufficient walking speed allowing older adults to safely navigate a pedestrian crossing of approximately 8-feet [21]. Two of the current older adults achieved a walking speed of $1.39 \mathrm{~m} \cdot \mathrm{s}^{-1}$ during their baseline 1-mile walk, outside the range set by Bazzona et al. [20], but above the threshold set by Asher et al. [21]. Thirteen participants had a walking speed greater than $1.78 \mathrm{~m} \cdot \mathrm{s}^{-1}$ at baseline, with one individual reaching a 1-mile walking speed of $2.19 \mathrm{~m} \cdot \mathrm{s}^{-1}$. Overall, this indicates participants had an adequate level of functional mobility to meet the requirements of daily living before the exercise programme commenced [2] [20]. Walking speed increased by $14 \%$ following 8- and 12-weeks of LTW (8-weeks: $1.90 \pm 0.19 \mathrm{~m} \cdot \mathrm{s}^{-1}$; 12-weeks: $\left.2.01 \pm 0.17 \mathrm{~m} \cdot \mathrm{s}^{-1}\right)$, with a $9 \%$ decrease in time to complete one mile by 12 -weeks $(13.5 \pm 1.3 \mathrm{mi}$ nutes). These improvements in 1-mile walking speed and time following treadmill walking were extensively higher than the speeds achieved by participants in Bazzona et al. [20]. However, the improved 1-mile walking speeds of men and women are comparable to the maximal walking speeds of older men (60-years: $1.93 \mathrm{~m} \cdot \mathrm{s}^{-1}$; 70-years: $2.08 \mathrm{~m} \cdot \mathrm{s}^{-1}$ ) over a distance of 25 -feet [22]. An enhanced walking speed during the RFWT is accounted for by improved gait characteristics. An $8 \%$ increase in stride frequency was reported following 12 -weeks of treadmill walking reflecting the increased walking speed.

Baseline predicted $\dot{V} \mathrm{O}_{2}$ max of the current participants $\left(22.8 \pm 5.0 \mathrm{~mL} \cdot \mathrm{kg}^{-1} \cdot \mathrm{min}^{-1}\right)$ suggests the women had a poor level of aerobic fitness for their age and men were fair-good $\left(33.9 \pm 5.4 \mathrm{~mL} \cdot \mathrm{kg}^{-1} \cdot \mathrm{min}^{-1}\right.$; [23]). This indicates, the women in particular, were aerobically unfit prior to participating in the study. Shephard [1] proposes the minimal required $\dot{V} \mathrm{O}_{2}$ max for independent living is $18 \mathrm{~mL} \cdot \mathrm{kg}^{-1} \cdot \mathrm{min}^{-1}$ for men and $15 \mathrm{~mL} \cdot \mathrm{kg}^{-1} \cdot \mathrm{min}^{-1}$ for women. One older female was below this threshold at baseline with a predicted $\dot{V} \mathrm{O}_{2}$ max of only 11 $\mathrm{mL} \cdot \mathrm{kg}^{-1} \cdot \mathrm{min}^{-1}$. However, this older female was living independently and reported no issues with activities of daily living as proposed by Shephard [1], leading to a potential limitation of the predictive test used, or this individual may not have been fully familiar with the 1-mile walk test after one familiarisation walk [16]. Overall, participants were of a similar baseline aerobic fitness to those participants in Seals et al., (25.6 \pm 4.6 $\mathrm{mL} \cdot \mathrm{kg}^{-1} \cdot \mathrm{min}^{-1}$; [24]), with a more superior level of aerobic fitness to those in Buchner et al. $(16.3 \pm 4.5$ $\mathrm{mL} \cdot \mathrm{kg}^{-1} \cdot \mathrm{min}^{-1}$; [8]) whom completed a screening process to intentionally recruit physically unfit older adults.

Endurance exercise by sedentary unfit individuals typically elicits a 5-20\% improvement in $\dot{\mathrm{V}}_{2} \max$ [25] [26]. Older women in both exercise groups show a $22 \%\left(27.9 \pm 1.9 \mathrm{~mL} \cdot \mathrm{kg}^{-1} \cdot \mathrm{min}^{-1}\right)$ increase in predicted $\dot{V} \mathrm{O}_{2} \max$ and an $11 \%\left(37.5 \pm 5.3 \mathrm{~mL} \cdot \mathrm{kg}^{-1} \cdot \mathrm{min}^{-1}\right)$ increase for older men. These increases in predicted $\dot{\mathrm{V}} \mathrm{O}_{2} \max$ enhanced the aerobic fitness classifications of both men (good-excellent) and women (fair-good) [23]. The observed improvement in aerobic capacity of these older adults is estimated to be $>1$ MET increase (Men: 9-10 METs; Women: 6 - 8 METs), which may translate into a 12\% reduced risk of mortality [27]. These results allow us to reject the hypothesis as both LTW and DTW produced similar improvements in predicted $\dot{\mathrm{V}} \mathrm{O}_{2}$ max for older adults. It has been previously demonstrated that older adults require $25 \%$ less oxygen during DTW in comparison to LTW at the same self-selected speed [12]. This would suggest an insufficient intensity, as a percentage of $\dot{\mathrm{V}} \mathrm{O}_{2} \max$ (37\%, [12]), to improve aerobic capacity in accordance with ACSM's guidelines [14], but this was not the case, as both groups had similar improvements. 
Such improvements in $\dot{\mathrm{V}} \mathrm{O}_{2}$ max are the results of adaptations across the cardiovascular, skeletal and respiratory systems [28]. An improved $\dot{\mathrm{V}} \mathrm{O}_{2}$ max for elderly adults is generally the result of an increase in muscle oxidative capacity [24] [29]. Skeletal muscle adaptations may cause such a change, augmented by an increased mitochondria, capillary density and muscle mass [24]. Twelve-weeks of cycling at $70 \% \quad \dot{V} \mathrm{O}_{2} \max \quad 3 \mathrm{~d} \cdot \mathrm{wk}^{-1}$ increased $\dot{\mathrm{VO}}{ }_{2}$ max by up to $6.0 \mathrm{~mL} \cdot \mathrm{kg}^{-1} \cdot \mathrm{min}^{-1}$ for older adults (65 years) the result of a $128 \%$ increase in muscle oxidative capacity and a change in arteriovenous oxygen difference [29]. The current participants had approximately a $4 \mathrm{~mL} \cdot \mathrm{kg}^{-1} \cdot \mathrm{min}^{-1}$ increase in $\dot{V} \mathrm{O}_{2} \max$. Such changes are likely the results of skeletal muscle adaptations, particularly for the DTW participants, as the load was less on the cardiovascular system in DTW. And, many studies provide evidence that the age-related reduction in aerobic capacity may be attributed by the loss of muscle mass and the development of aerobic exercise prescriptions that enhance both muscle mass and aerobic capacity has important implications for older adults [30].

Physiological measurements show that the 1-mile walk was completed quicker, without an increased heart rate at the end of the walk. This suggested beneficial cardiovascular adaptations, with aerobic conditioning resulting in proportionally lower heart rates at a given absolute exercise intensity [31]. However, mean HR over the latter half of the 1-mile walk was significantly higher after the walking programme. Additionally, oxygen consumption during the 1-mile walk remained unchanged from baseline to post. An improved economy during the 1-mile walk could be the result of an improved muscle oxidative capacity and changes in motor unit recruitment patterns [32]. This also reflected the suggestions earlier that an increased $\dot{V} \mathrm{O}_{2} \max$ in older adults was due to changes in arterio-venous oxygen difference [24] [29]. Minute ventilation $\left(\dot{V}_{\mathrm{E}}\right)^{2}$ increased following 12 -weeks of treadmill walking indicating an increase in tidal volume and respiratory frequency. This would reflect the increased intensity by which the 1-mile walk was completed i.e. decreased walking time. Although these respiratory adaptations occurred, it did not change oxygen utilization or any other metabolic or cardiovascular parameters. As oxygen consumption remained similar from baseline to 12 -weeks and predicted $\dot{\mathrm{V}} \mathrm{O}_{2}$ max increased, we speculated that oxygen consumption during the 1-mile walk, as a percentage of predicted $\dot{\mathrm{V}} \mathrm{O}_{2}$ max would be decreased. But this was not the case as oxygen consumption remained between $60 \%-65 \%$ of predicted $\dot{\mathrm{V}} \mathrm{O}_{2} \max$ from baseline to 12-weeks, and the explanation for this finding was not known.

Some potential limitations of the study should be considered. The main limitations were the assessment of $\dot{\mathrm{V}} \mathrm{O}_{2} \max$ using a predictive, sub-maximal test and the small subject numbers. In future, a maximal, symptom limited graded exercise test may be used. However, due to the population group being assessed in the current study, a sub-maximal test was an appropriate and convenient method. Additionally, a sedentary control group was not used to assess the effects of the intervention. This study design was utilized based on the suggestions of Booth and Lees [33]; they suggested that a physically active control group could be used as opposed to a sedentary control, because a healthy, physically active group of participants were at a reduced risk of illness, and physical inactivity was already well-known to be a major cause of disease and lower level of functional capacity. Therefore, future research might investigate the changes in using a treadmill based test, specific to the intervention utilized, but also a more frail elderly population group, and match intensity of the exercise interventions for LTW and DTW.

In conclusion, the results of this study demonstrated that a treadmill walking programme at a self-selected walking speed could improve 1-mile walk performance and aerobic capacity. Additionally, both LTW and DTW elicited similar aerobic adaptations following 8- and 12-weeks of walking for 30-minutes $3 \times$ per week, even though DTW was at a lower cardiovascular load [12]. This enabled us to accept the hypothesis that both concentric and eccentric endurance exercises at self-selected intensity provided similar improvement in aerobic capacity. Such results could prove valuable for not only older adults, but also individuals recovering from cardiovascular complications. An exercise programme at a self-selected intensity and a reduced cardiovascular load could not only enhance aerobic fitness but also have a positive effect on functional independence for such individuals.

\section{References}

[1] Shephard, R.J. (2009) Maximal Oxygen Intake and Independence in Old Age. British Journal of Sports Medicine, 43, 342-346. http://dx.doi.org/10.1136/bjsm.2007.044800

[2] Daley, M.J. and Spinks, W.L. (2000) Exercise, Mobility and Aging. Sports Medicine, 29, 1-12. http://dx.doi.org/10.2165/00007256-200029010-00001

[3] Tanaka, H., Desouza, C.A, Jones, P.P., Stevenson, E.T, Davy, K.P. and Seals, D.R. (1997) Greater Rate of Decline in 
Maximal Aerobic Capacity with Age in Physically Active vs. Sedentary Healthy Women. Journal of Applied Physiology, 83, 947-953.

[4] Hagberg, J.M. (1987) Effect of Training on the Decline of $\mathrm{VO}_{2}$ max with Aging. Federation Proceedings, 46, 18301833.

[5] Booth, F.W., Laye, M.J. and Roberts, M.D. (2011) Lifetime Sedentary Living Accelerates Some Aspects of Secondary Aging. Journal of Applied Physiology, 111, 1497-1504. http://dx.doi.org/10.1152/japplphysiol.00420.2011

[6] Gault, M.L, Clements, R.E. and Willems, M.E.T. (2012) Functional Mobility of Older Adults after Concentric and Eccentric Endurance Exercise. European Journal of Applied Physiology, 112, 3699-3707. http://dx.doi.org/10.1007/s00421-012-2338-4

[7] Gault, M.L. and Willems, M.E.T. (2013) Isometric Strength and Steadiness Adaptations of the Knee Extensor Muscles to Level and Downhill Treadmill Walking in Older Adults. Biogerontology, 14, 197-208. http://dx.doi.org/10.1007/s10522-013-9423-X

[8] Buchner, D.M, Cress, M.E., de Lateur, B.J, Esselman, P.C, Margherita, A.J, Price, R. and Wagner, E.H. (1997) A Comparison of the Effects of Three Types of Endurance Training on Balance and Other Fall Risk Factors in Older Adults. Aging (Milano), 9, 112-119.

[9] Thomas, E.E, De Vito, G. and Macaluso, A. (2007) Speed Training with Body Weight Unloading Improves Walking Energy Cost and Maximal Speed in 75- to 85-Year-Old Healthy Women. Journal of Applied Physiology, 103, 15981603. http://dx.doi.org/10.1152/japplphysiol.00399.2007

[10] Hall, C.W, Holmstrup, M.E, Koloseus, J., Anderson, D. and Kanaley, J.A. (2012) Do Overweight and Obese Individuals Select a "Moderate Intensity" Workload When Asked to Do So? Journal of Obesity, 2012, Article ID: 919051. http://dx.doi.org/10.1155/2012/919051

[11] Parfitt, G., Rose, E.A. and Burgess, W.M. (2006) The Psychological and Physiological Responses of Sedentary Individuals to Prescribed and Preferred Intensity Exercise. British Journal of Health Psychology, 11, 39-53. http://dx.doi.org/10.1348/135910705X43606

[12] Gault, M.L, Clements, R.E. and Willems, M.E.T (2013) Cardiovascular Responses during Downhill Treadmill Walking at Self-Selected Intensity in Older Adults. Journal of Aging and Physical Activity, 21, 335-347.

[13] LaStayo, P.C, Marcus, R.L, Dibble, L.E, Smith, S.B and Beck, S.L. (2011) Eccentric Exercise versus Usual-Care with Older Cancer Survivors: The Impact on Muscle And Mobility-An Exploratory Pilot Study. BMC Geriatrics, 11, 5. http://dx.doi.org/10.1186/1471-2318-11-5

[14] American College of Sports Medicine (2000) ACSM's Guidelines for Exercise Testing and Prescription. Lippincott, Williams \& Wilkins, New York.

[15] Haycock, M., Sabapathy, S., Morris, N., Gass, G. and Minahan, C. (2009) Self-Selected Walking Intensity of Healthy Older Women (65 - 75 yr) during Treadmill and Over-Ground Walking. Medicine \& Science in Sports \& Exercise, 41, 362. http://dx.doi.org/10.1249/01.MSS.0000355651.33242.2c

[16] Fenstermaker, K.L, Plowman, S.A. and Looney, M.A. (1992) Validation of the Rockport Fitness Walking Test in Females 65-Years and Older. Research Quarterly for Exercise and Sport, 63, 322-327. http://dx.doi.org/10.1080/02701367.1992.10608749

[17] Gault, M.L., Clements, R.E. and Willems, M.E.T. (2009) Effects of Wearing the Cosmed K4b2 Metabolic System on 1 Mile Walking Performance in Older Adults. Journal of Human Kinetics, 21, 41-48. http://dx.doi.org/10.2478/v10078-09-0005-6

[18] Wanta, D.M, Nagle, F.J and Webb, P. (1993) Metabolic Response to Graded Downhill Walking. Medicine \& Science in Sports \& Exercise, 25, 159-162. http://dx.doi.org/10.1249/00005768-199301000-00022

[19] Little, R.J. and Rubin, D.B. (1989) The Analysis of Social Science Data with Missing Values. Sociological Methods \& Research, 18, 292-326. http://dx.doi.org/10.1177/0049124189018002004

[20] Bazzano, C., Cunningham, L.N, Cama, G. and Falconia, T. (1995). Physiology of 1-Mile Walk Test in Older Adults. Journal of Aging and Physical Activity, 3, 373-382.

[21] Asher, L., Aresu, M., Falaschetti, E. and Mindell, J. (2012) Most Older Pedestrians Are Unable to Cross the Road in Time: A Cross-Sectional Study. Age and Ageing, 41, 690-694. http://dx.doi.org/10.1093/ageing/afs076

[22] Bohannon, R.W. (1997) Comfortable and Maximum Walking Speed of Adults Aged 20-79 Years: Reference Values and Determinants. Age and Ageing, 26, 15-19. http://dx.doi.org/10.1093/ageing/26.1.15

[23] The Cooper Institute (1997) The Physical Fitness Specialist Manual. The Cooper Institute for Aerobics Research, Dalla.

[24] Seals, D.R., Hagberg, J.M., Hurley, B.F., Ehsani, A.A. and Holloszy, J.O. (1984) Endurance Training in Older Men and Women. I. Cardiovascular Responses to Exercise. Journal of Applied Physiology, 57, 1024-1029. 
[25] Blumenthal, J.A., Emery, C.F., Madden, D.J, George, L.K, Coleman, R.E., Riddle, M.W, McKee, D.C, Reasoner, J. and Williams, R.S. (1989) Cardiovascular and Behavioural Effects of Aerobic Exercise Training in Healthy Older Men and Women. Journal of Gerontology, 44, M147-M157. http://dx.doi.org/10.1093/geronj/44.5.M147

[26] Posner, J.D, Gorman, K.M., Klein, H.S and Woldow, A. (1986) Exercise Capacity in the Elderly. The American Journal of Cardiology, 57, 52C-58C. http://dx.doi.org/10.1016/0002-9149(86)91027-1

[27] Kokkinos, P., Myers, J., Faselis, C., Panagiotakos, D.B, Doumas, M., Pittaras, A., et al., (2010) Exercise Capacity and Mortality in Older Men: A 20-Year Follow-Up Study. Circulation, 122, 790-797. http://dx.doi.org/10.1161/CIRCULATIONAHA.110.938852

[28] Taylor, A.H, Cable, N.T., Faulkner, G., Hillsdon, M., Narici, M. and Van Der Bij, A.K. (2004) Physical Activity and Older Adults: A Review of Health Benefits and the Effectiveness of Interventions. Journal of Sports Sciences, 22, 703-725. http://dx.doi.org/10.1080/02640410410001712421

[29] Meredith, C.N., Frontera, W.R., Fisher, E.C., Hughes, V.A., Herland, J.C., Edwards, J. et al. (1989) Peripheral Effects of Endurance Training in Young and Old Subjects. Journal of Applied Phsyiology, 66, 2844-2849.

[30] Harber, M.P., Konopka, A.R., Undem, M.K., Hinkley, J.M., Minchev, K., Kaminsky, L.A. et al. (2012) Aerobic Exercise Training Induced Skeletal Muscle Hypertrophy and Age-Dependent Adaptations in Myofiber Function in Young and Older Men. Journal of Applied Physiology, 113, 1495-1504. http://dx.doi.org/10.1152/japplphysiol.00786.2012

[31] Spina, R.J. (1999) Cardiovascular Adaptations to Endurance Exercise Training in Older Men and Women. Exercise \& Sport Sciences Reviews, 27, 317-332. http://dx.doi.org/10.1249/00003677-199900270-00012

[32] Holloszy, J.O. and Coyle, E. (1984) Adaptations of Skeletal Muscle to Endurance Exercise and Their Metabolic Consequences. Journal of Applied Physiology: Respiratory, Environmental and Exercise Physiology, 56, 831-838.

[33] Booth, F.W. and Lees, S.J. (2006) Physically Active Subjects Should Be the Control Group. Medicine \& Science in Sports \& Exercise, 38, 405-506. http://dx.doi.org/10.1249/01.mss.0000205117.11882.65

\section{Abbreviations}

BIA, bioelectrical impedance analysis

BP, blood pressure

DTW, downhill treadmill walking

$\mathrm{HR}$, heart rate

$\mathrm{HR}_{\text {max }}$, maximum heart rate

$\mathrm{HR}_{\text {reserve, }}$, heart rate reserve

LTW, level treadmill walking

RFWT, Rockport fitness walking test

RHR, resting heart rate

RER, respiratory exchange ratio

SSWS, self-selected walking speed

$\dot{V}_{\mathrm{E}}$, minute ventilation

$\dot{V} \mathrm{O}_{2}$, oxygen consumption

$\dot{V} \mathrm{CO}_{2}$, carbon dioxide production

$\dot{V} \mathrm{O}_{2 \text { max }}$, maximal oxygen uptake 